be reframed as not solely a lack or inability of these students but as possible consequences of neo-racism within the host culture. The most common cases are subtle ones and may include "harmless" jokes about a foreign accent or culture, excluding international students from classroom participation and social events, and using dominant frames of reference that leave out other cultural perspectives.

Ultimately, successful international student exchange is not simply a headcount of international student enrollments but also involves the cultural and intellectual exchange of international students. This means paying greater attention to the experiences of those already enrolled and fostering positive, enriching interactions between international students and members of the host institutions.

\section{The Partnership for Higher Education in Africa}

\section{Narciso Matos}

Narciso Matos is chair of the International Development Program at the Carnegie Corporation of New York and former secretary general of the Association of African Universities and rector of the University Eduardo Mondlane, in Mozambique. E-mail: NMA@carnegie.org.

Tn 2000, the Ford Foundation, the John D. and Catherine T. 1 MacArthur Foundation, the Rockefeller Foundation, and the Carnegie Corporation of New York launched an initiative to coordinate their support of higher education in Africa: the Partnership for Higher Education in Africa (PHEA). Responding to, and contributing to, trends of democratization, public policy reform, and the increasing participation of civil society organizations in a growing number of African countries, the partnership aimed to support the priority given to education-especially the indispensable contribution of higher education to social and economic development. The foundations wanted to encourage the innovation and creativity witnessed in "universities on the move."

While maintaining each foundation's unique strategic focus, the four agreed to work together toward accelerating the processes of modernization and institutional revitalization of universities in selected African countries, committing \$IOO million over five years. The issues to be addressed included curriculum reform; training and retraining of faculty members and technical and support staff; participation of African experts in international research and scientific networks; improved internal governance and accountability; increased access for students and higher quality of academic activities; diversification of sources of universities' income and greater responsiveness to societal needs; and improved contribution to the alleviation of poverty.
To ensure that PHEA interventions address the priorities identified by leaders of higher education in Africa, the foundations have adopted a multilayered strategy. First, they selected seven countries-Ghana, Kenya, Mozambique, Nigeria, South Africa, Tanzania, and Uganda-that accentuated trends of democratization, public policy reform, participation of civil society organizations, priority of higher education, and innovative university leadership. These criteria do, unfortunately, omit countries and institutions that would qualify for support under other valid but less-stringent requirements.

Second, PHEA consulted with university leaders through such means as workshops organized to develop studies of their higher education systems. Local experts and scholars authored the studies, which were reviewed by leaders and experts from other partnership countries. This process has allowed members to benefit from the insight and guidance of African colleagues, has limited the negative influences of power imbalances stemming from foundations' control of financial resources, and has helped build a level of trust and comfort between foundations and African leaders.

Third, we have learned to celebrate accomplishments by attributing success to the agency of the grantees rather than to the foundations. Visibility is essential for successful interventions to encourage other African governments, donors and investment agencies to support higher education and to reassure the foundations' trustees and leaders that money is being effectively invested. On the other hand, too much publicity might raise the expectations of other needy institutions and countries, leading policymakers to steer resources away from partnership universities toward other pressing needs not presently addressed by donors.

Fourth, we decided that our investment should be allocated

While maintaining each foundation's unique strategic focus, the four agreed to work together toward accelerating the processes of modernization and institutional revitalization of universities in selected African countries, committing $\$ 100$ million over five years.

first and foremost to select African institutions, which would then identify partners in other countries and allocate resources for working with them. Admittedly, this decision is hard to enforce when many well-intentioned leaders and experts from the United States and other developed nations approach the partnership or individual foundations with truly valid and viable ideas. But to remain true to the principle of working directly with African institutions, even promising initiatives must be denied support.

An assessment of PHEA in 2005 revealed that since 2000 , the four foundations have invested \$150 million, 50 percent 
above their initial pledge, benefiting 40 universities in 6 countries, with 23 countries receiving significant funding for systemic change. Nearly one-third million students benefited directly, including more than I, ००० female scholarship beneficiaries. The assessment also found that the foundations invested more on higher education than would have been possible without the partnership.

One leading initiative is in the area of information and communications technology identified as a priority intervention at a joint workshop with the UN Economic Commission for Africa. With an initial investment of more than $\$ 5$ million, the partnership commissioned the African Virtual University to consolidate bandwidth demand from several universities and negotiate its acquisition from satellite companies at a significantly lower cost. No single foundation would have had the network and the human resources to start and sustain this effort over time.

PHEA has also attracted the attention of other foundations and agencies. The William and Flora Hewlett Foundation and the Andrew W. Mellon Foundation formally joined the partnership in April 2005. The six foundations have pledged to continue the partnership though 2010 and to invest \$200 million over the next five years, expanding the number of beneficiary countries to include Kenya, Egypt, and Madagascar. Four special initiatives will receive joint support: (a) provision of broadband and utilization of information and communication technology to improve access to information and production of knowledge in African universities; (b) development of research on higher education innovations, institutional transformation,

While the African universities will ultimately determine whether our efforts have been successful, there are many signs that our collaboration is bearing fruit.

and universities' contribution to development; (c) support to regional networks for research and training; and (d) a university leadership forum to expose academic leaders and policymakers to relevant science and technology innovation.

Despite our best efforts, the partnership has not done enough to coordinate its initiatives with wider and more farreaching strategies such as those for poverty alleviation, the 2020 national development plans, the Millennium Development Goals, or the sector-development approaches by which government-to-government resources are allocated according to national priorities. Foundations have the advantage of operating "outside" the bureaucracy of government-togovernment relations and the flexibility to experiment with new and sometimes risky ideas and projects; however, this does not diminish the importance of keeping a country's strategy in mind. Equally, the partnership has a long way to go in coordinating with other African regional institutions (e.g., the
African Development Bank), the World Bank, and other major development agencies that also support education.

When the partnership was formed, there was, as is often the case with new endeavors, some skepticism about the venture. As we have worked together and honed our relationship over these past five years, even the most cautious observers began to appreciate the benefits of collaboration. While the African universities will ultimately determine whether our efforts have been successful, there are many signs that our collaboration is bearing fruit.

\section{Academic Staff Attrition at African Universities}

\section{WISDOM J. TETTEY}

Wisdom J. Tettey teaches in the Faculty of Communication and Culture at the University of Calgary. Address: Faculty of Communication and Culture, University of Calgary, Calgary, AB, Canada $T_{2} N_{1} N_{4}$. E-mail: tettey@ucalgary.ca.

$\Lambda$ frican universities continue to contend with a shortage of A academic staff and so do not seem capable of mobilizing the intellectual strength needed to drive capacity-building efforts on the continent. To address this situation of a declining professoriate, a study was conducted at five African universities, with support from the World Bank, to identify mechanisms for university staff retention that are feasible in Africa under currently severe financial constraints. The institutions were the Universities of Botswana, Ghana, Ibadan, Kwa-Zulu Natal, and Makerere. The study was limited to particular fields of expertise, which have been identified as the most vulnerable to brain drain: health sciences, engineering, business, economics, and computer/information science. We sought to understand factors behind staff attrition, analyze what the case study institutions are doing to address them, and suggest feasible responses to the problem. This article focuses on the first two objectives.

Self-administered survey questionnaires were distributed to all academic staff in the targeted disciplines, at each of the selected universities, who did not hold administrative positions. They were anonymously completed, and the response rates were as follows: University of Botswana, I6.2 percent; University of Ghana, 20.I4 percent; Kwa-Zulu Natal, I9 percent; and the University of Ibadan, 62 percent. In addition to the surveys, personal interviews were conducted with department heads, deans, and provosts in charge of the units representing the targeted fields of expertise, as well as with pro/deputy vice-chancellors, vice-chancellors, and presidents of faculty associations.

Following the surveys and interviews, we organized work- 